NOTAS Y DISCUSIONES

\title{
Libertad de vivir *
}

\author{
LORENZO PEÑA Y TXETXU AUSÍN ** \\ Instituto de Filosofía del CSIC-Universidad Europea de Madrid
}

RESUMEN. Hay dos tipos de bienes y derechos: de bienestar y de libertad. Los primeros, irrenunciables, acarrean deberes positivos, de dar o hacer. Los derechos de libertad, en cambio, sólo imponen a otros deberes negativos, dejando a su titular libre para ejercerlos o no según quiera. Sostenemos que el derecho a la vida es un derecho de libertad. De ahí se sigue que no es obligatorio aceptar el don de la vida salvo cuando el ordenamiento permite a los progenitores presumir el futuro consentimiento retroactivo del nuevo ser humano por nacer. Cuando las circunstancias hagan irrazonable tal presunción, es ilícita toda acción causal que contribuya a ese nacimiento salvo únicamente la acción voluntaria y libre de la madre de no abortar - por ser ése un derecho suyo-. Matizamos nuestra teoría y la articulamos en un enfoque gradualista que da cuenta de la existencia de conflictos jurídicos.

\section{El caso judicial de Nicolás Perruche}

$\mathrm{Al}$ recorrer la enorme discusión doctrinal, mediática y ensayística en torno al celebérrimo caso de Nicolás Perruche (NP en
ABstract. There are two sorts of goods and rights; wellbeing rights and freedom rights. The latter may be renounced by the right-holder and enjoin abstention duties (or negative duties) upon other people. Wellbeing rights impose positive duties on other people and may not be relinquished by the right-holder. We claim that life is a freedom right. Therefore, there is in general no duty to live. The gift of life has to be accepted only insomuch as the presumption of future backwards acceptance by our parents was reasonable. When such is not the case, the new-born is entitled to claim that his right not to live was violated and to demand a compensation from any person, barring his or her mother, having causally contributed to his/her birth. We hedge our theory with several qualifications within the framework of a gradualistic approach to rights and duties.

lo sucesivo), hallamos una serie de posiciones fundamentales.

Recordemos los hechos más sustanciales. Graves errores de diagnóstico llevaron a una señora que estaba encinta a no ejer-

\footnotetext{
* Este trabajo se ha desarrollado en el marco del proyecto de investigación «Un estudio lógico-gradualista de los conflictos normativos» financiado por el Ministerio de Ciencia y Tecnología (BJU2002-1042).

**1orenzo@ifs.csic.es - fjose.ausin@fil.cin.uem.es
} 
cer el derecho que le confiere la ley francesa de interrupción del embarazo. El diagnóstico correcto hubiera mostrado la probabilidad de que hubiera contraído la rubeola ya iniciada la gestación. El resultado fue el nacimiento de NP, un niño que enseguida reveló estar aquejado por gravísimas discapacidades, como consecuencia causal de esa rubeola materna. Tras una larga historia judicial, el tribunal supremo francés, la Corte de Casación, reconoció el derecho a una indemnización tanto para los esposos Perruche como para el niño NP, representado legalmente por su madre y que demandaba reparación por la discapacidad.

La opinión se dividió entre perruchistas (defensores de la sentencia de la Corte de Casación) y antiperruchistas (impugnadores de la misma sobre la base, ya sea del Derecho positivo vigente en la hermana república, ya — más a menudo- de principios jurídicos o metajurídicos —en definitiva de un derecho natural).

Tras la tempestad mediática desatada, la Asamblea Nacional, por unanimidad, aprobó una ley que prohibía en adelante aducir como perjuicio o daño el mero hecho del nacimiento: la vida es un don valioso, cualesquiera que sean las circunstancias.

En el frente antiperruchista se han sostenido principalmente dos líneas. La una es una oposición débil: los errores de diagnóstico, aunque sí constituían una negligencia o impericia profesionales, no causaron el daño que sufre el niño. Y sólo cabe tener que indemnizar por un daño que uno ha causado, no por uno que no ha causado.

La otra línea antiperruchista —que es la central en nuestro análisis- es que, puesto que NP no hubiera podido nacer no-discapacitado, sólo ha sufrido un daño (la discapacidad) si es la vida misma lo que constituye un daño para él. Porque no hay nada aducido de lo que él hubiera podido estar exento; sin nacer, no hubiera existido; sin existir, no estaría exento de discapacidad. Mas la vida, el ser, es preferible al no-ser, al no-vivir, no pudiendo nunca constituir un daño o un desvalor. Eso se desprende del principio de la dignidad del ser humano. Hablar, pues, de un daño sufrido por NP es juzgar que su vida no vale la pena de vivirse, y que, por ende, estaría mejor muerto que vivo; y, por analogía, es sostener otro tanto con relación a cuantos se hallen en un nivel de discapacidad igual o mayor.

Nótese que hay dos hebras en la segunda línea. La una es que, aléguenlo o no, aquello que, en definitiva, han de considerar los perruchistas como un daño es la propia vida, el nacimiento. La otra hebra se abstiene de atribuir a los perruchistas esa visión (la de que el nacimiento es un daño para NP), mas sí sostiene que el daño que aducen es uno que, siendo, en la realidad de los hechos, inseparable del nacimiento - salvo por abstracción-, es algo que, en el caso que nos ocupa, está indisociablemente ligado con ese nacimiento, de suerte que no puede haber una causa del uno sin el otro (nada ha podido causar un nacimiento sin discapacidad de NP ni su congénita discapacidad como un efecto diverso del nacer y vivir); así, sólo se podía prevenir la discapacidad previniendo el nacimiento (abortando).

En la línea perruchista se han formulado varias posiciones ${ }^{1}$ :

1. ${ }^{a} \quad$ Muy minoritaria: la de los poquísimos que se han atrevido a decir que para NP hubiera sido mejor no nacer; que la vida, siendo un bien, no lo es a cualquier precio; y ese bien del no-nacer de NP sería, sin duda, uno para los padres, especialmente para la madre, mas también uno para NP, quien así se vería libre de los sufrimientos de por vida a que lo ha condenado ese nacimiento. Eso sí, una vez que se ha producido, se trata de aliviar el daño, compensando, asegurando, mediante una reparación adecuada, que pueda disponer 
siempre de recursos para hacer sobrellevable su estado, en la medida de lo posible.

2. ${ }^{\text {a }}$ Muy común ha sido el parecer de que la Corte de Casación había aplicado correctamente la legislación francesa, o al menos había actuado, en el margen asignado a la labor jurisprudencial, dentro de la ley, por lo cual era pernicioso aducir en contra de su fallo una instancia de principios metajurídicos. Así, una buena parte de los perruchistas ha salido por los fueros del viejo juspositivismo francés amenazado por la invocación de pautas que establecerían criterios jurídicos por encima de la ley y que, por lo tanto, estarían al albur de las opiniones de los jurisconsultos ${ }^{2}$.

3. ${ }^{\mathrm{a}}$ Lo más socorrido ha sido el concepto de ficción jurídica ${ }^{3}$. Se ha aducido que el mundo jurídico es diverso del de la realidad natural, incluso de la realidad humana natural, o cuasinatural. La ficción, el corte, se produce cuando la ley, en aras de la regulación ordenada de las relaciones humanas, y sobre la base de la soberanía legislativa, pone donde la realidad quita o viceversa. Ese recurso a la ficción jurídica se suele combinar con el juspositivismo que inspira la posición $\left(2 .^{\mathrm{a}}\right)$, evocada en el párrafo precedente. En concreto, se aducen dos posibles recursos a la noción de ficción jurídica: el uno es en lo tocante a la causalidad: el vínculo de causa a efecto entre la falta médica y la discapacidad de NP no sería el nexo causal natural, sino el relevante según la ley; el otro recurso es a la noción de sujeto o persona, que la ley determina según pautas en parte sustraídas a la continuidad y el orden naturales, de suerte que el sujeto de derecho NP puede y debe pensarse jurídicamente sin la discapacidad, como teniendo ésta accidentalmente y por efecto de la falta médica, aunque en la realidad humano-natural no sea así.

4. ${ }^{\mathrm{a}}$ Una posición aislada, mas propuesta por una de las mejores representantes del perruchismo (Marcela Iacub) ${ }^{4}$ consiste en sostener que NP sí hubiera podido existir y vivir sin la discapacidad, porque la identidad o individuación del sujeto humano no es la del ser biológico o cuerpo humano resultante de la unión de un óvulo y un espermatozoide, sino la proyección de un proyecto parental. NP hubiera podido nacer antes o después, de otro óvulo y otro espermatozoide (de los mismos padres, eso sí), sin dejar de ser él. Si su madre hubiera abortado el zigoto del cual ha salido su cuerpo, no por ello habría impedido la venida al mundo del mismo NP en otro momento. Aunque ésta es una tesis metafísica, también responde en parte al juspositivismo que inspira a las dos precedentes, al confiar (aparentemente) a la ley la tarea de escoger la concepción metafísica del ser humano que conviene; la ley de interrupción voluntaria del embarazo y la legislación bioética llevarían a esa concepción. Pero ese recurso al juspositivismo en buena medida desfigura o hace dudoso el carácter metafísico de la propuesta.

\section{La vida, un derecho de libertad}

La posición que vamos a defender se inscribe resueltamente en la línea perruchista. Guarda una proximidad con la línea superminoritaria $\left(1 .^{\mathrm{a}}\right)$ (la tesis de que para NP hubiera sido mejor no nacer y que, por lo tanto, el hacerlo nacer ha sido un mal para él), pero con una apreciable diferencia: no vamos a sostener que la vida sea en ese caso un daño, o que hubiera sido mejor no nacer en ese caso; lo que vamos a sostener es que se ha conculcado el derecho de NP a escoger haber nacido o no haber nacido; que se le ha impuesto haber nacido, cuando las condiciones no permitían en absoluto presumir su consentimiento. Y que la vida es un bien de libertad. Es un derecho sin deber. Sólo es lícito hacer donación de ella cuando las condiciones permiten razonablemente presumir 
el ulterior consentimiento retroactivo del afectado.

Hay dos géneros de derechos: derecho a algo, X, acompañado del derecho a no-X, y derechos que no son así. A los primeros podemos llamarlos «derechos de libertad». Los otros son los que Carnelutti llamó «derechos-deberes».

Una clasificación usual en la teoría de los derechos humanos es la que deslinda los derechos de libertad de los derechos de bienestar. Creemos que es correcta, porque nos parece enteramente sostenible y convincente que, en ese campo, los únicos derechos-deberes son los de bienestar.

No es que todos los derechos humanos que no sean de bienestar sean derechos de libertad, dejando a la persona libre de ejercerlos o no. Eso no es así. Cualquier deber para con la comunidad implica el derecho de cumplir ese deber, o sea: el derecho a realizar el acto o la omisión en que consista ese cumplimiento.

Lo que sí sucede es que los derechos básicos del individuo, aquellos que no se derivan meramente del cumplimiento de deberes, o son de bienestar o son de libertad; y los de bienestar aparentemente no son de libertad.

La diferencia la han solido establecer otros autores sólo en lo siguiente: mientras que un derecho de libertad deja al sujeto libre de ejercer o no ciertas acciones y sólo prohíbe a los demás estorbárselo o impedírselo (deberes negativos), en cambio, los derechos de bienestar son derechos positivos que autorizan al individuo a obtener algo, y que obligan a otros, o a la colectividad, a facilitarle su obtención; imponen, pues, deberes positivos a otros.

Siendo correcto todo eso, a nuestro juicio (al menos en líneas generales), hay que preguntarse si, no obstante, el individuo tiene derecho de no ejercer sus derechos de bienestar. Si tiene derecho a no trabajar, a no tener morada, a no disfrutar de cuidado a la salud, a no instruirse, a no comer, a no vestirse. ¿Hay un derecho a la des- gracia, a la enfermedad, al hambre, al dolor?

No hay tales derechos. No porque (como seguramente pensó Aristóteles) sea imposible que un hombre quiera no ser feliz, sino porque, siendo perfectamente posible, es ilícito. La razón es que hay deberes para con uno mismo. Y el principal deber para con uno mismo es el de no labrar la propia desgracia. Tales deberes vienen de tres fuentes:

- La primera fuente es que el yo presente no puede sacrificar a su antojo al yo futuro ${ }^{5}$. Cada individuo, en cada momento, aunque es el mismo ser que el que será un tiempo después, está algo desdoblado de éste, y ese desdoblamiento — sin constituir una dualidad de personas o de entidades, sino meramente una dualidad de estados sucesivos de la misma persona- sí marca límites a lo que a uno le es lícito hacer contra su yo futuro. El bienestar del yo futuro ha de estar a salvo de atentados del yo presente; al menos en alguna medida; medida que puede ser la de que al yo presente le esté vedado escoger deliberadamente la desgracia del yo futuro.

- La segunda fuente es que tenemos deberes para con los demás. Cada uno está inserto en una red de relaciones sociales; labrar la propia desgracia entraña causar a otros un daño; en unos casos más, en otros menos. Como mínimo, en un estado social del bienestar —en uno en el que rija el principio de solidaridad-, causar la propia desgracia (la propia enfermedad, el propio sufrimiento, la propia desocupación laboral, la propia situación de desamparo) va a forzar a la colectividad a un socorro adicional en perjuicio de todos.

- La tercera fuente es un principio de reciprocidad cuasi-contractual: desde que vamos creciendo y nos vamos integrando como seres conscientes a la comunidad humana en la que estamos insertos, vamos 
entrando en un contrato colectivo transgeneracional en el que se aúnan y convergen los esfuerzos de todos para el bien de cada uno y para el bien común. Atentar contra el bien propio no sólo perjudica a ese bien común (del cual forma parte), sino que defrauda las expectativas de quienes nos han ayudado, esteriliza los esfuerzos y los sacrificios de las generaciones gracias a cuyo aporte hemos llegado donde estamos.

Por todo ello, cualquiera que sea el grado de exigibilidad de la conducta concreta promotora del propio bienestar, en general no es lícita la opción por el propio malestar. Un hombre llevado por el (perfectamente concebible) odio a sí mismo no tiene legalmente en su mano mutilarse, optar por su propio sufrimiento, infligirse una grave enfermedad (a lo personaje de André Gide). Tales conductas estarán sancionadas o perdonadas, mas son contrarias al ordenamiento jurídico de cualquier sociedad normal y civilizada.

Notemos de paso que la libertad es un derecho de bienestar, no de libertad (por paradójico que ello pueda sonar). No se tiene derecho a no ser libre. Y es que hipotecar la libertad constituye un tremendo atentado contra el bienestar, esterilizando y frustrando los sacrificios de sucesivas generaciones en lucha por la libertad.

En cambio, hay una esfera de actos, de omisiones y de situaciones que involucran al individuo en la cual éste es libre para hacer o no hacer, estar o no estar en tal situación. ¿Cuál es esa esfera?

Negativamente, podemos determinarla como la de bienes que no sean de bienestar, bienes que no determinen la felicidad. O sea, bienes en los que la opción por el no-ejercicio no determine infelicidad, sufrimiento, malestar; aunque siempre cabe que indirectamente también haya repercusiones en el bienestar, mas sin un vínculo de causalidad directo.

Pensamos todos en derechos como: el de asociación y no-asociación: a cada indi- viduo, en un sistema político de libertades (y hasta, en alguna medida, en otros sistemas políticos) se le deja asociarse o no con quienes lo deseen para las actividades lícitas de vida o acción común (desde contraer matrimonio hasta integrar un club de lecturas poéticas); el derecho de reunión; el derecho de votación (aunque hay sistemas que prohíben la no-votación); el derecho de comunicación (y el de no comunicación, pues la obligación de expresarse fue excepcional y ha ido cayendo en desuso en las sociedades modernas); el derecho de participación en los asuntos públicos o de la comunidad (aunque a veces se impone forzosamente tal participación); o el derecho de seguir residiendo en el mismo lugar o de mudarse; o el de escoger tal profesión.

Podemos conjeturar que son actividades íntimas, en las que la personalidad, la individualidad, la intimidad del sujeto cuenta más que el aporte o no-aporte al bien común. Eso nos daría un segundo criterio para determinar los bienes de libertad: serían bienes de la esfera íntima, o bienes en los que el carácter de intimidad es más acusado que la repercusión social (que también puede darse).

Sentados esos dos criterios (el negativo de no ser bienes de bienestar ni que involucren directamente el bienestar común; y el positivo de ser bienes que afectan más a la intimidad del sujeto), podemos preguntarnos dónde colocar el derecho a la vida.

¿Es un derecho de bienestar? ¿Es un derecho de libertad?

A favor de considerarlo un derecho de bienestar puede razonarse diciendo que la felicidad o el bienestar suponen la vida; sin vida no hay bienestar. Mas que supongan la vida no quiere decir que la vida sea un componente de la felicidad. La vida no es uno de los elementos de la calidad de la vida. Justamente se distingue entre vivir más (tiempo) y tener más calidad de vida. 
También puede argumentarse diciendo que para persistir en la vida valen las tres razones que imponen obligaciones para con uno mismo (el principio de solidaridad, el respeto del yo-futuro y el deber de no malograr lo que los demás han hecho por nosotros). Sin embargo, es dudoso que la muerte de uno acarree cargas a la comunidad (como las acarrearía la propia enfermedad grave); en cuanto al deber para con el yo futuro, es un poco dudoso que el yo presente esté comprometido a que exista ese yo futuro (estará, sí, comprometido a no causar la desgracia de tal yo futuro); por otro lado, los esfuerzos de los demás, que hemos de agradecer y a los que hemos de corresponder, no nos van a obligar a vivir siempre (entre otras razones porque es imposible) ni determinan la duración de la vida, sino sólo la calidad de ésta, en cuanto esté en la mano de uno mismo ${ }^{6}$.

Frente a esos dos argumentos, puede alegarse (se nos antoja que más razonablemente) que el derecho a la vida es un derecho de libertad, porque la vida es lo más subjetivo de todo, es el núcleo de la intimidad individual, es el centro del ámbito más propio e irreductible del individuo; el ámbito en el que los demás parecen más fuera de lugar y en el que, a solas, cada uno está más en lo suyo.

\section{El derecho a no vivir}

Si son correctas las consideraciones del apartado anterior, entonces hay no sólo un derecho a la vida, un derecho a vivir, sino también un derecho a no vivir.

Mas ¿qué es no vivir? Para un ser que vive en un lapso temporal dado, $t$, el no vivir puede referirse a no vivir en $t$, $o$ antes de $\mathrm{t}$, o después de $\mathrm{t}$.

Podría pensarse que el no vivir que nos interesa aquí, relativo a los derechos que se tienen, es un no vivir futuro, el no vivir después de $t$, porque el derecho mira al futuro y no al pasado, define lo que es lícito hacer o tener en lo sucesivo, no lo que es lícito haber tenido o hecho en el pasado.

No es así. El derecho, ciertamente, mira más al futuro que al pasado, y está construido en aras del futuro. Mas, en primer lugar, hay un derecho relativo al presente. Lo que uno está haciendo en un tiempo $\mathrm{t}$ puede que sea lícito, puede que no lo sea. El que está matando o robando está perpetrando un acto ilícito; no sólo es ilícito que lo vaya a seguir haciendo, sino también que lo esté haciendo.

En segundo lugar, todo acto presente es en parte pasado y en parte futuro. $\mathrm{Si}$ un acto que uno está realizando es ilícito, lo es que lo haya (en parte) realizado ya, igual que lo es que lo siga ejecutando. Y, si una situación es lícita, no sólo es lícito que siga disfrutando uno en el futuro de tal situación, sino también que ya haya en parte disfrutado de ella.

Mas, si es lícito que haya sucedido lo que en parte ya ha sucedido (y en parte sucederá), no se ve por qué no va a ser lícito el haber sucedido otras cosas que sucedieron.

Unas veces, fue siempre lícito que sucedieran. Otras veces, era ilícito, mas es ahora lícito que hayan sucedido, porque ha cambiado la ley. Así, si en un país está prohibida la reunión para debatir temas políticos, quienes lo hagan hacen algo ilícito; mas, si luego cambia la ley, deja de ser ilícito haberlo hecho. Ahora es lícito haberse reunido, aunque entonces no fue lícito reunirse. Luego decir «es lícito haber hecho tal cosa» no equivale a decir «fue lícito hacer tal cosa». Hay derechos (y hay deberes) que se adquieren retrospectiva o retroactivamente. El principio de irretroactividad no es un principio metajurídico de validez general, sino a lo sumo una pauta (ponderable y no forzosamente prevalente en todos los casos) en el campo sólo del derecho punitivo y sancionador.

Cuando son atropellados los derechos de una persona, no sólo es ilícito lo que 
se le hace en el momento de hacérselo, sino que también es ilícito después habérselo hecho. La persona violada conserva su derecho a no haber sido violada. $\mathrm{La}$ persona torturada tiene derecho a no haber sido torturada. El ignorante tiene derecho a no haber sido ignorante, a haber recibido instrucción.

Por eso, quien comete un acto ilícito contra los derechos de alguien, sigue estando en una relación ilícita con respecto a ese alguien, porque la víctima conserva siempre su derecho a no ser víctima, a no haber sido víctima.

Siendo eso así, en general, el derecho a no vivir, si se da $-\mathrm{y}$ en tanto en cuanto se dé- no tiene por qué ser meramente el de no seguir viviendo en el futuro, sino que incluye el de no vivir ahora, y por lo tanto el de haber dejado de vivir ya antes, o incluso retrospectivamente haber muerto o no haber nacido.

Si uno tiene el derecho de dejar de vivir, no se ve cómo negarle el derecho a haber dejado ya de vivir; o, yendo más lejos, el de no haber nacido.

$\mathrm{Y}$ es que, cuando se menciona la paradoja en que consiste hablar del derecho a no nacer (si X disfruta de ese derecho, no nace, por consiguiente, no existe, ni hay tal ente, $\mathrm{X}$, que disfrute ese derecho), no sólo se soslayan sin discusión las muchas soluciones a ese problema propuestas en diversos círculos de la filosofía analítica (como el noneísmo de Richard Sylvan entre otras) ${ }^{7}$, sino $-\mathrm{y}$ es esto lo que nos interesa- se omite el problema del derecho que tiene un ser que ha nacido, $\mathrm{X}$, a no haber nacido; como el derecho que tiene una mujer violada a no haber sido violada.

No vale alegar en contra de eso que lo pasado es irremediable $\mathrm{y}$, por ende, necesario. Y no vale, en primer lugar, porque ser ya irremediable o indeshacible no equivale a ser necesario (salvo en alguna concepción temporalizada de la necesidad, que no suele aceptar casi ningún autor hoy día). Es, sí, una verdad necesaria que, en este mundo, no se puede estar en un lapso temporal en el que ha pasado previamente tal cosa y que eso no haya pasado. Es imposible vivir en el siglo $\mathrm{xx}$ en un mundo en el que ya se ha inventado el ferrocarril un siglo antes no viviendo en un mundo donde se ha inventado el ferrocarril. Mas desde luego no es imposible que no se hayan inventado en el siglo XIX. Lo único imposible es que, habiéndose inventado, no se hayan inventado.

El pasado es, pues, irremediable, mas no necesario. Muchas cosas podrían no haber pasado.

Mas es que, en segundo lugar, lo necesario no sólo no es obligatorio, sino que al revés: lo imposible es lícito. La licitud de lo imposible, de lo absolutamente imposible, se deduce con ayuda de estas premisas y reglas de inferencia ${ }^{8}$ :

1) Hay acciones, A, tales que es lícito A y también es lícito abstenerse totalmente de A (acciones libres).

2) Cuando dos cosas son lícitas, es lícita la conyunción de ambas.

3) De que A sea necesariamente equivalente a B se sigue que la licitud de A es igual a la licitud de B.

Puesto que hay acciones libres, y es totalmente imposible hacer una cosa absteniéndose completamente de hacerla, y puesto que hacerla y abstenerse totalmente de hacerla es un imposible absoluto que necesariamente equivale a cualquier imposible absoluto, resulta que cualquier imposible absoluto es lícito.

Por eso, basta que una sociedad crea que un rumbo de acción es absolutamente imposible para que levante cualquier prohibición al respecto ${ }^{9}$.

Por lo tanto, la inevitabilidad del pasado no lo hace obligatorio. Nadie tiene obligación de que algo le haya sucedido simplemente porque le haya sucedido. 


\section{La presumibilidad del consentimiento}

Si la vida es un bien de libertad, no se puede imponer contra la voluntad del interesado. Los bienes de libertad son tales que hace legalmente falta el consentimiento del beneficiado ${ }^{10}$.

No siempre puede darse el consentimiento para un bien de libertad. Así, aunque la salud no es un bien de libertad -sino uno de bienestar-y no es libre, sí es libre someterse a una intervención quirúrgica. Mas la ley prevé casos en los que se prescinde de ese consentimiento; casos en los que es legítimo presumir el futuro consentimiento retroactivo - si bien cabe la posibilidad de que, llegado el momento, no se dé. Aun así, la acción ha sido lícita, porque era legal y razonable presumir ese consentimiento. Casos de traumatismo, inconsciencia, urgencia ${ }^{11}$.

Hay muchos actos que es lícito hacer en nombre de otro a título de gestor de negocios y aun sin mediar previa autorización del interesado, aunque sean actos de asociación o comunicación que entran de lleno en la esfera de la libertad. Son actos que se llevan a cabo con el consentimiento presunto del interesado; una presunción razonable basada en inducción y en deducción. Hay extralimitaciones del poder de un mandatario que también valen, porque era razonable presumir el ulterior consentimiento retroactivo del mandante.

Si todos tenemos derecho a vivir o no vivir, si tenemos derecho a morir ${ }^{12}$, y a haber muerto ya, y a no haber nacido, eso no nos autoriza, sin embargo, a ir en contra de quienes nos hicieron nacer; porque éstos estaban legalmente autorizados - dadas las circunstancias- a presumir nuestro futuro consentimiento retroactivo; como así es efectivamente en el 99 por 100 de los casos.

Cuando las circunstancias hacen totalmente dudosa la previsión de tal consentimiento, es ilícito imponer la vida.
No porque en tales circunstancias la vida haya de ser un mal, o sea, mejor no vivir que vivir. Ni siquiera necesariamente porque, en tales circunstancias, tenga que ser preferible una situación de no vivir antes que la concreta situación de vivir así y asá (que eso no es lo mismo que vivir a secas, ni siquiera cuando sea imposible o humanamente irrealizable el vivir de otro modo). Sobre qué sea preferible cabe opinar. No es cierto que carezca de sentido la comparación ni que carezcamos de criterios ampliamente compartidos, aunque ni son a priori ni son estáticos ni son unánimemente aceptados ${ }^{13}$.

No, la razón por la cual es, en ciertos casos, ilícito imponer el don de la vida es la de que, en esos casos, no hay base razonable para presumir el ulterior consentimiento del afectado.

$1 .^{\circ} \quad$ No puede haber tal consentimiento si la vida que se impone va inevitablemente acompañada de un estado de carencia de razón o de tal disminución de la razón que nada que emanara de un ser así podría venir considerado como consentimiento.

2. ${ }^{\circ}$ No puede haber consentimiento cuando se impone la vida a un ser humano que no pueda nunca expresarse significativamente, que no pueda manejar la comunicación lingüística.

3. ${ }^{\circ}$ No puede haber consentimiento válido cuando el ser al que se impone la vida no va a poder tener una percepción del mundo que cuente como una experiencia humana que se aproxime a la normal, al menos en algunos aspectos.

4. ${ }^{\circ}$ No puede haber consentimiento válido cuando se impone la vida a un ser humano que con toda probabilidad va a perecer antes de alcanzar el uso de razón.

5. ${ }^{\circ}$ No ha de presumirse el consentimiento (aunque sí podría llegar a darse) cuando se impone la vida a un ser humano en condiciones tales que será inevitable para él un enorme e incurable sufrimiento, 
un continuado dolor, si eso es perfectamente previsible (no un caso fortuito ni fuerza mayor) y resulta médicamente insuperable en el estado actual de la ciencia.

6. ${ }^{\circ} \quad$ Por lo mismo, no ha de presumirse en una situación - conocida de antemano, inevitable y vitalicia para el nasciturusen la que sea razonable hacerse esa pregunta de si sería mejor no haber nacido, y eso tanto si —en lo tocante a esta última pregunta- nos decantamos por el sí como si nos decantamos por el no.

7. ${ }^{\circ} \mathrm{Ni}$ puede presumirse el consentimiento cuando se impone la vida a un ser humano abocado a la situación de esclavo de por vida ${ }^{14}$.

8. ${ }^{\circ} \mathrm{Ni}$ puede presumirse el consentimiento cuando el acto de procreación o generación determina una relación de filiación que en sí es odiosa o insoportable o humillante (engendramiento por violación, o procreación incestuosa en las sociedades que, como la nuestra, prohíben el reconocimiento legal de tal filiación genética); o sea, en casos en que para el futuro ser humano ese engendramiento sea fuente de dolor o de frustración ${ }^{15}$.

Nótese que el argumento que profesamos a favor de la no presumibilidad del consentimiento en los casos $5 .^{\circ}$ al $8 .^{\circ}$ no es la de que, a nuestro juicio, en tales casos sea mejor no nacer. Menos aún la de que creamos que el sujeto tiene obligación de no nacer, o de, una vez nacido, no vivir, o no seguir viviendo. Ni la de que estemos persuadidos de que tales vidas no valen la pena de vivirse. Lo que creemos es que hay en tales casos una base razonabilísima para sospechar que eso es así y para imaginar que, si (en muchos casos, por desgracia, contrafácticamente) el afectado pudiera tener un momento de lucidez, él mismo tal vez así lo vería. Eso hace que no quepa presumir el consentimiento, nada más. No hace a ese consentimiento, cuando y en la medida en que pueda darse, irracional o merecedor de condescendencia.

\section{Circunstancias en las que más valdría no haber nacido}

No es verdad — según suelen aducir en una rama de su argumentación los antiperruchistas, aunque en contradicción con la otra rama- que carezca de sentido decir lo de que más valdría no haber nacido.

- En primer lugar, porque de hecho se dice, y se ha dicho. "Bueno le fuera al tal hombre no haber nacido» (Ev. de S. Mateo, 26,24); «bueno le fuera a aquel hombre si nunca hubiera nacido» (Ev. de S. Marcos, 14,21). Algo que se dice tan frecuentemente podría ser un sinsentido. Mas hay que probarlo. A falta de prueba, lo verosímil es que tenga sentido.

- En segundo lugar, no puede probarse que sea un sinsentido porque dizque sea lógicamente imposible atribuir una cualidad a un inexistente. Y no puede probarse así porque hay tratamientos lógico-metafísicos que proponen hacer eso, y que no son obviamente rechazables.

- Además, y en tercer lugar, hay que distinguir el no nacimiento de la inexistencia o incluso de la no vida. El zigoto, el feto y el ser humano nacido son un solo y mismo ente en tres fases de su desarrollo. El ordenamiento jurídico no otorga al zigoto (ni siquiera al feto) el rango de un titular de derechos en sentido estricto. Mas en virtud del principio lógico-jurídico de correlación entre derechos y deberes, al prohibir a otros hacerle ciertas cosas, sí le está otorgando derechos (pues al fin y al cabo es un ser vivo, que siente en determinado grado, y que está dotado de intereses, no un ser inerte como una piedra ni siquiera como una planta). Que no se complete el ciclo gestativo y que se efectúe un aborto no entraña, pues, que no haya habido tal ser del cual se diga que sería mejor para él no nacer o no haber nacido, o sea, no haber visto completada su gestación ${ }^{16}$.

- En cuarto lugar, con respecto a un ser humano normal que sufre una desgra- 
cia tiene sentido decir que sería mejor para él haber muerto la víspera, o sea, haber vivido un día menos. O la antevíspera. O la anteantevíspera. Y así sucesivamente. Hasta de un ser sumamente desgraciado desde el día siguiente a su nacimiento podemos decir (sea verdad o no, pero con sentido) que sería mejor no haber vivido más de un día; o más de una hora; o más de un minuto; y así sucesivamente. ¿Por qué va a ser un completo sinsentido decir que sería mejor no haber vivido fuera del seno materno ni un minuto? ${ }^{17}$.

- En quinto y último lugar, para que tenga sentido decir (con verdad o sin ella) de alguien, $X$, que le sería mejor no haber vivido, no hemos de representarnos un mundo $\sin \mathrm{X}$ y otro con $\mathrm{X}$ tales que $\mathrm{X}$ está mejor en el primer mundo que en el segundo; aunque hay tratamientos lógico-filosóficos que permiten decir esas cosas - tratamientos que no aceptamos, pero que no son disparatados-, no los necesitamos. Lo único que necesitamos pensar es el mundo con X, cuando el balance de bienes y males, valores y desvalores, que afectan a $\mathrm{X}$ es tal que, con una vida más corta $-\mathrm{y}$ en el extremo de duración cero- ese balance podría concebirse como menos negativo.

Y es que, cuando a un bien lo acompaña un mal, el balance puede ser positivo o negativo, según qué prevalezca. Así, aunque el bien es bien y no mal, aunque es valioso y no desvalioso, en ciertas circunstancias puede ser mejor no tenerlo. Las donaciones requieren el consentimiento del donatario; la ley puede imponer una presunción de consentimiento en ciertos casos. Mas está claro que hay donaciones que son regalos envenenados (con o sin mala intención del donante); que hay herencias y donativos que es mejor no aceptar, por bueno que sea abstractamente lo donado o heredado. Hay vidas de tal sufrimiento que éste compensa y excede el bien de la vida misma.

\section{El derecho a no vivir tiene límites}

La libertad de vivir o no vivir (que, por una regla de lógica jurídica, implica el derecho a vivir si se escoge vivir y el derecho a morir si se escoge morir) no significa que no haya también, en contradicción con esa libertad, un deber de vivir en ciertos casos.

Para los adeptos de la lógica deóntica estándar el mundo de las normas está exento de contradicciones. Por el contrario, una lógica jurídica atenta a la realidad compleja de lo normativo ha de reconocer grados de licitud y de prohibición, y por lo tanto la posibilidad (y aun la realidad) de conflictos normativos ${ }^{18}$.

Una acción A puede ser en algún grado lícita a la vez que otra acción B también lo es en algún grado. Al mismo tiempo, puede suceder que la realización de A impida o estorbe gravemente la de $\mathrm{B}$ al margen de la voluntad de los agentes involucrados en B. En virtud de una regla de lógica jurídica (el principio de no vulneración, que prohíbe impedir o estorbar el ejercicio de derechos ajenos), A, en esa medida, será una acción prohibida. Mas habíamos supuesto la licitud de A. ¿En qué quedamos?

Quedamos en que A es ambas cosas, lícita e ilícita. Más lícita que ilícita si el grado de estorbo o impedimento de B es pequeño o si el propio grado de licitud de $\mathrm{B}$ es bajo. Más ilícita que lícita en caso contrario (o sea, si B es una acción de alto grado de licitud y A la estorba mucho o impide del todo).

Similarmente, podemos tener una acción A que es, de suyo, y en virtud de una norma vigente, lícita, a la vez que A tiene un efecto causal indirecto, B, que está prohibido. Supongamos que A causa a C, que causa a B. Si B es ilícito, entonces -por la regla lógico-jurídica del efecto lícito, a saber, que es ilícita toda acción que cause efectos prohibidos- $\mathrm{C}$ lo es. 
Mas entonces A lo es, por lo mismo, contra la hipótesis de la licitud de A.

Mas puede ser que A tenga ambas determinaciones jurídicas, por contradictorias que sean: licitud e ilicitud. De nuevo más licitud si el nexo de causalidad es de menor fuerza causatoria o si es bajo el grado de ilicitud del efecto causado. Más ilicitud en caso contrario.

Que un derecho sea derecho incondicional es una cosa. Que sea absoluto o ilimitado es otra. Hay derechos que no se tienen incondicionalmente. Así, el derecho a visitar el Palacio de Aranjuez el próximo sábado está condicionado, entre otras cosas, a que no se hayan adelantado otros visitantes cuyo número colme la cuota permitida por razones de conservación del patrimonio histórico. El derecho de un individuo de contraer matrimonio con otro está condicionado, entre otras cosas, al consentimiento de éste y a la ausencia de impedimentos legales (como el estar uno de los dos actualmente unido por un vínculo matrimonial con el otro o con una tercera persona).

Todo derecho meramente condicional tiene límites. Es lícito ejercerlo sólo cuando se cumplen las condiciones. En rigor, a falta de tales condiciones no se da el derecho a la acción, sino el derecho a que, si llegan a darse las condiciones, se produzca esa acción. El contenido del derecho, su dictum, se expresa en un enunciado condicional, «Si B, A». Por una regla válida de lógica jurídica, una vez que se cumplan las condiciones, B, se pasa a tener el derecho incondicional a la acción, A.

Mas un derecho incondicional puede y suele tener también límites. Aquí no se trata de un límite determinado por la presencia de las condiciones, pues no hay tales, ya que estamos ante un derecho incondicional. No, el límite lo marca la concurrencia de otros derechos y deberes que colisionan con el derecho considerado.

Esa colisión es una contradicción jurídica, toda vez que se traduce en que una misma opción sea a la vez lícita e ilícita (en virtud de las aludidas reglas lógico-jurídicas). La colisión puede tener diversos orígenes: las diversas y dispersas fuentes del derecho; lagunas; promulgamientos contradictorios; protección legal de intereses en conflicto; principios jurídicos también en conflicto uno con otro; el surgimiento de nuevas conexiones causales (lo cual es especialmente real en el caso de los problemas bioéticos, donde las nuevas técnicas dan lugar a vínculos causales antes inexistentes); la realización parcial de supuestos de hecho a tenor de la cual ciertas situaciones jurídicas surjan y no surjan: surgen en tanto en cuanto se cumple el supuesto de hecho; no surgen, en tanto en cuanto ese cumplimiento es sólo parcial, y conlleva algún grado de incumplimiento.

Hay una serie de deberes que tenemos para con los demás y para con nosotros mismos que pueden determinar — por las citadas reglas de lógica jurídica- un deber de vivir, en conflicto con nuestro derecho a no vivir.

1. ${ }^{\circ}$ Tenemos ciertos deberes resultantes de compromisos contractuales o cuasicontractuales, que nos ligan, ante todo, con nuestro consorte; luego, con nuestros hijos o nuestros padres cuando tenemos a los primeros a nuestro cuidado o estamos bajo el cuidado de los segundos. También nos unen vínculos contractuales con nuestros socios y asociados, colegas, personas que han aportado esfuerzos o sacrificios a una empresa común y a quienes tenemos deber de no defraudar.

2. ${ }^{\circ}$ En último término, tenemos un deber (en algún sentido contractual también) para con la sociedad, de la cual somos socios, partícipes, a la que tanto debemos y en la que tal vez estemos desempeñando tareas que quedarían negativamente afectadas por nuestra ausencia.

3. ${ }^{\circ}$ Tenemos deberes para con nuestro yo futuro. Ciertamente entre el yo presente y el futuro no hay diferencia personal, ni 
el yo futuro tiene el mismo título que un sujeto ajeno a erguirse exigiendo el respeto a sus derechos contra el yo presente. Mas de la identidad o mismidad de personas no se sigue la total ausencia de dualidad o conflicto de intereses o de preferencias, porque hay intereses y preferencias de un individuo (o de un grupo) relativizadas al tiempo, o sea: de un individuo o grupo en ese trecho temporal. Aunque las reclamaciones de nuestro yo futuro no pueden oponerse a nuestro yo presente del modo como se le opondrían las reclamaciones de un tercero, eso tampoco otorga plenos poderes al yo presente contra el yo futuro. En la medida en que hay bienes de bienestar que puede esperarse razonablemente que estén al alcance del yo futuro, el acortamiento de la vida que impida su consecución es un atentado ilícito contra ese yo futuro, al menos cuando el balance razonablemente esperable de bienes y males se inclina resueltamente por los bienes.

4. ${ }^{\circ}$ Tenemos deberes no contractuales cuyo cumplimiento exige que sigamos viviendo; p. ej., deberes de resarcir a otros por daños previamente causados.

Todo eso no convierte al derecho a la vida en un derecho de bienestar; no lo sustrae a la esfera de la libertad. Pero sí marca límites a esa libertad, porque hace entrar en juego deberes que colisionan con el derecho a no seguir viviendo.

Básica y esencialmente la vida está en el ámbito de la libertad individual, mas hay condiciones en que es razonable exigir - en aras del cumplimiento de otros deberes prevalentes- el no ejercicio de ese derecho a no vivir; pero también hay condiciones en las que exigirlo es imponer un fardo demasiado gravoso; no por la vida en sí, que es siempre buena, sino por otros factores que inevitablemente hayan de acompañar la vida de alguien.

Así, un padre de familia sin duda tiene un deber de imponerse seguir viviendo, y superar cualquier situación de depresión, desánimo, apatía, rabia o similar, cuando pesan sobre él cargas de cuidado familiar, cuando hay seres que él ha hecho nacer y que quedarían desamparados sin su sostén. Mas tal exigencia, que limita el derecho del padre a poner fin a sus días, tiene ella misma límites. ¿Sería razonable exigir eso a un padre para quien cada día es un infierno -imaginemos que por una grave e incurable dolencia neuro-psíquica-, sin ninguna esperanza (ni objetiva ni subjetiva) de mejoría? Es muy dudoso.

En casos así, o bien prevalece el derecho a morir o bien al menos es inexigible la conducta conforme a la norma que imponga la obligación de seguir viviendo. Disminuiría la ilicitud de la terminación de la propia vida, aun sin anularse del todo ${ }^{19}$.

Similarmente, un soldado en un ejército enfrascado en una dura batalla puede que esté obligado a seguir viviendo y luchando, aun teniendo que soportar indecible dolor y penalidad y aunque le fuera más cómodo y agradable poner piadosamente fin a ese sufrimiento, más allá del cual no hay para él ninguna esperanza (ni objetiva ni subjetiva) de curación ni de reposo. Es un caso límite. Si se trata de una guerra defensiva contra una injusta invasión foránea, seguramente es así. Ahí estamos ante el mayor sacrificio que se puede legítimamente exigir a alguien; no sacrificar la vida, sino sacrificar la no vida, sacrificar el disfrute del derecho a no vivir.

Mas claramente es un caso extremo, felizmente excepcional. Sea como fuere, nada parecido se da en los casos que constituyen el principal asunto estudiado en este artículo. En general, las personas a las que se está aquí discutiendo el derecho a no vivir (y a no haber vivido) son personas que no pueden estar ligadas por compromisos u obligaciones de los tipos enumerados, ni con relación a sí mismas ni a los demás. Esas personas (gravemente discapacitadas para siempre desde el nacimiento) no tienen obligación alguna de vivir ni de haber vivido. 
Diferente es el caso de, p. ej., personas concebidas por un acto de procreación que sea una violación, o un incesto. En tales situaciones es perfectamente posible que, una vez nacido el fruto de esa relación ilícita, se sobreponga al trauma, al menos en parte, o no llegue nunca a estar gravemente afectado por él, sino que sea una persona normal en sus relaciones con los demás. Su derecho a no haber nacido viene limitado por la medida del sufrimiento que le haya producido de por vida ese nacimiento. Y desde luego puede que, frente a él, se yergan ciertos deberes con vigor y exigibilidad mayores; deberes que pueden derivarse de derechos ajenos - por la regla de no vulneración.

\section{El derecho de la madre a no abortar}

Los antiperruchistas alegaron que, de permitirse a alguien demandar a un médico por haber causado su propio nacimiento dañoso ${ }^{20}$, entonces, por las mismas, se tendría que permitir que eventualmente demande a sus propios padres, lo cual era un escándalo, porque implicaba un atentado contra la naturaleza humana: iun hijo descastado pleiteando contra su madre por haberle dado la vida!

Los perruchistas suelen replicar que se ha transfigurado el caso, reemplazando la situación real (en la que la madre ha expresado su deseo de abortar si hay probabilidades de haber contraído la rubeola y, por lo tanto, de malformación del feto) por una hipotética en la que sería la madre la que no hubiera querido abortar a pesar de la probabilidad de malformación grave.

Perruchistas y antiperruchistas han estado de acuerdo en que la madre no tiene obligación alguna de abortar, es más, unos y otros han estado casi siempre de acuerdo en que, cuando es lícito el aborto eugenésico (mal llamado «terapéutico»), es sólo la madre quien tiene derecho a él, no el feto ni el futuro niño; que ese derecho sólo protege el interés materno, no un interés fetal ni uno del eventual ser humano que pueda nacer si no se aborta.

Por una vez, vamos a contribuir a la unanimidad sumándonos a la tesis de que a la madre le es siempre lícito no abortar, aunque no es una permisión sin ningún tipo de límite; de hecho, sostenemos que el feto o el futuro niño tienen derecho a que se lleve a cabo el aborto, porque es injusto imponer la continuación de la vida intrauterina hasta el nacimiento de un ser humano cuando es irrazonable presumir su ulterior consentimiento retroactivo.

Ahora bien, ese derecho del feto a no seguir viviendo y el derecho del futuro niño a no haber nacido entran en colisión con el derecho de la madre a no abortar. Derecho, éste sí, en interés propio. La mujer embarazada tiene siempre un derecho prevalente, cualesquiera que sean las circunstancias, a no abortar, pase lo que pasare, sean cuales fueren las causas del embarazo, haya sido lícito, o no, el acto de procreación. Una vez producida la fecundación en su seno, ella tiene un derecho vital a que se complete el ciclo gestatorio, si entiende que eso es lo correcto y lo adecuado para ella por razones sanitarias, biológicas, morales, psicológicas o cualesquiera otras. Por encima del interés y del derecho del futuro niño a no nacer está el de la mujer embarazada a no abortar, a completar su función maternal. Eso sí, tal decisión impone obligaciones adicionales de cuidado materno una vez completada la gestación. Es decir, la madre, con su decisión de continuar con el embarazo, contrae el deber de atender adecuadamente al hijo que nace en unas condiciones de vida especialmente difíciles. Y si esto se hace con pleno conocimiento e información, no ha lugar a demanda o reclamación.

Mas, si bien es prevalente el derecho de la mujer encinta a no abortar —y sería inviable una demanda contra ella por ese motivo del hijo futuro-, en cambio, sí procede una demanda contra el padre si éste 
ha impedido el aborto deseado por la madre. También cabe una demanda contra un acto de engendramiento ilegal, ya sea una violación (sólo contra el padre, porque la madre no consintió), ya sea un incesto ${ }^{21}$.

Puede haber casos más complejos, p. ej., un acto de procreación en situaciones en las que hay alguna grave incompatibilidad de los gametos de los progenitores, y éstos lo saben, de lo cual resulta una alta probabilidad de drepanocitosis u otra tara congénita. En tales casos es dudosa la presumibilidad del ulterior consentimiento retroactivo. En el estado actual, lo normal es que los jueces estimen que no hay elementos probatorios concluyentes a favor de la irrazonabilidad de la presunción; lo cual justifica la conducta procreativa de los padres. Sin embargo, eso puede depender de la gravedad de la tara, de la probabilidad a parte ante de que ésta se llegue a producir y de otras circunstancias ${ }^{22}$.

Para cerrar este apartado, cabe debatir el caso hipotético de un zigoto humano, o humanoide, producido artificialmente en probeta por algún método de ingeniería genética a sabiendas de la alta probabilidad (o eventualmente certeza) de una grave dolencia del ser humano por nacer - tras, supongamos, la implantación del zigoto en el útero de una mujer (sin que nos importe ahora la cuestión del consentimiento informado de ésta). La dolencia que consideramos es la insensibilidad a los analgésicos, acompañada de una incurable malformación dolorosa. A cambio, tal vez ese ser humano(ide) tendría dotes excepcionales de algún tipo. No nos importa tampoco cuál pueda ser el procedimiento de ingeniería genética (podemos imaginar una combinación de partes de varios gametos, o una especie de anticlonación).

Los pro-vida a machamartillo, los antiperruchistas, tienen que sostener que, siendo siempre la vida mejor que la no-vida, y siendo ese ser humano eventual tal que él no existiría sin esas afecciones, no puede quejarse de ellas, ni puede demandar a los perversos científicos que inventaron o quisieron experimentar el procedimiento genético en cuestión. Es imposible, en la argumentación antiperruchista, sostener el derecho de ese niño a lamentarse de que se le ha infligido el nacimiento cuando era irrazonable presumir su ulterior consentimiento. Los científicos malvados serían en tal caso verdaderos autores del ser de ese niño.

Aunque la hipótesis es puramente ficticia, no cabe duda que en los próximos decenios van a ser factibles cosas así o más peregrinas. Ya hoy, sin llegar a eso, pueden, para la fecundación in vitro, escogerse deliberadamente gametos con conocida incompatibilidad - sea por maldad, ganas de experimentar o lo que sea. Tal selección es posible pero ilícita (y seguramente ningún científico la ha hecho ni la hará nunca). Es ilícita, ante todo, porque vulnera el legítimo interés del fruto eventual de esa fecundación a no ser procreado; y a, si es procreado, no sufrir una gestación que se complete por el nacimiento.

Conque, si la madre tiene siempre un derecho prevalente a no abortar, en cambio nadie más tiene un derecho prevalente a producir el engendramiento o el nacimiento en condiciones en las que sea inverosímil el ulterior consentimiento retroactivo del nacido. Ni el padre, ni los médicos ni cualesquiera terceros que pudieran técnicamente intervenir. Tanto menos cuanto más inverosímil sea ese consentimiento ulterior.

\section{El derecho a la vida de las personas jurídicas}

Todo nuestro tratamiento en estas páginas ha estado consagrado a la libertad de vivir de las personas humanas físicas. Conviene hacer unas escuetas consideraciones sobre la vida de las personas jurídicas.

No pretendemos poner en el mismo plano al individuo y al grupo (o colectivo). 
Lo que sí creemos es que se superó hace tiempo la visión reduccionista que reputaba a los colectivos como ficciones útiles. Los colectivos existen de veras; tienen una existencia a la que, metafóricamente, se llama «vida social», la cual, sin ser vida, es un ser con ciertos rasgos similares a los de una vida humana. Los colectivos tienen intereses, ejercen acciones y omisiones, incurren en responsabilidades, son titulares de derechos y sujetos de obligaciones.

$\mathrm{Si}$ aceptamos que asociarse o no forma parte de la esfera de libertad individual, la constitución de una sociedad habrá de estar condicionada al consentimiento (previo o simultáneo) de los individuos que vengan abarcados por esa sociedad. Mas tal libertad de no asociarse no siempre ha sido reconocida y aún hoy tiene límites legales ${ }^{23}$. Vamos ahora a prescindir de la presuposición de que exista tal libertad. Vamos a formular una reclamación más débil que la libertad individual de noasociación, a saber: que, aunque ésta no existiera, debería haber un derecho de los entes colectivos a no existir, y por lo tanto a que no se les imponga forzosamente la existencia social sin su consentimiento colectivo presunto.

El ser social, la vida colectiva, es mejor que la falta de ser social o de vida colectiva. Hay un valor intrínseco de ese ser social; valor tanto mayor cuanto más relevancia tiene el colectivo en la vida humana. Principalmente significativos son dos extremos: la pareja humana y la humanidad. Mas hay muchos otros colectivos importantes, cada uno con un derecho limitado a la vida colectiva $^{24}$.

Los pro-vida deberían aplicar sus razonamientos a la vida del grupo; p. ej., de la pareja. Si no lo hacen, la verdad es que parece una inconsecuencia, dados sus principios.

Ese razonamiento analógico sería así: la vida matrimonial es mejor que la no-vida matrimonial. Una pareja cuya constitución ha venido determinada por ciertas causas no puede quejarse de un rasgo de esa unión conyugal sin el cual ésta no existiría; ni puede demandar a otros por haber causado la formación de la pareja cuando era previsible ese rasgo negativo.

Así, tomemos una sociedad donde se casa a los jóvenes sin su consentimiento, por su bien. Casan a Dermiz con Yolhaz, siendo previsible su incapacidad para tener una relación matrimonial normal. La pareja Dermiz-Yolhaz lleva a juicio a los decisores que impusieron esa unión conyugal, pidiendo una indemnización; están de acuerdo en seguir viviendo juntos (ya que en esa sociedad no hay divorcio ni anulación matrimonial), mas piden una compensación por el daño causado. Los jueces (que serían, por hipótesis, pro-vida) sentencian que la pareja no puede quejarse de tener una vida conyugal, sin la cual no existiría — siendo la vida conyugal más valiosa que la ausencia de ella; ni puede, por ende, reprochar a nadie haber determinado su nacimiento al mundo de la sociedad humana.

Podríamos formular parodias similares en lo tocante a otros colectivos, como sociedades anónimas, cooperativas, partidos políticos, comunidades religiosas. Ninguna podría quejarse de que se la hizo existir injustamente o en circunstancias que no hacían presumible el ulterior consentimiento colectivo ${ }^{25}$.

Todo eso puede parecer peregrino. Los pro-vida a ultranza se aferrarán, sin duda, al argumento de la dignidad: el ser humano individual es digno; los colectivos, no ${ }^{26}$. Sin embargo, quiera decir «dignidad» lo que quisiere, no se ve por qué no son dignos los matrimonios, los grupos de cooperación humana; si los colectivos carecen de dignidad, también tendrá esa carencia la propia humanidad. Lo cual es absurdo.

El paralelismo es perfectamente adecuado. Si un grupo se queja de que se lo haya forzado a existir cuando su consentimiento no era presumible, lo hace con sobrada razón; porque, aunque la vida de 
grupo es un bien, aunque, más en particular, es valiosa la vida matrimonial, o lo es la vida de cooperación o de dedicación conjunta a un ideal, hay casos en que, habida cuenta de todo, puede ser preferible que no exista tal vida colectiva en particular, cuando su existencia va inevitablemente acompañada de males, siendo negativo el balance; o incluso cuando, sin llegar a serlo, había base para no presumir el consentimiento retroactivo del colectivo al que se haya impuesto la existencia desde arriba.

En resumen, la existencia de un ente colectivo ha de ser voluntaria, en el sentido de que por lo menos ha de requerirse la voluntad colectiva de que exista ese vínculo social $^{27}$; por lo cual no se le puede imponer existencia más que cuando sea presumible el ulterior consentimiento retroactivo ${ }^{28}$.

\section{Conclusiones: positivismo y jusnaturalismo}

Nuestro recorrido argumentativo nos ha llevado a la conclusión de que la vida es un bien de libertad; es un derecho que, en general, no comporta el deber de ejercer tal derecho.

Así, hemos defendido la sentencia de la Corte de Casación en el caso de NP, refutando la tesis de los pro-vida a ultranza. Lo hemos hecho sin abrazar el peligroso y escurridizo expediente de querer emancipar al derecho vigente por voluntad del legislador de cualesquiera principios que enmarquen la función antropológica del derecho (cual lo desean tantos perruchistas).

No deseamos recaer en el error de que son lo mismo la ley promulgada y el derecho. Lo que sucede es que los antiperruchistas tienen una concepción estrecha de la vida humana, de los valores, de la función socio-antropológica del derecho. Ven todo eso con un prisma unilateral, que pretende evacuar las contradicciones, que des- conoce las colisiones y que incluso no clasifica convenientemente los bienes en las dos clases de los de libertad y los de bienestar.

La angosta y sesgada posición antropológica de los antiperruchistas ignora que también son facetas de la vida las de la muerte y la opción por no vivir, por no haber vivido; facetas naturales, normales, legítimas, que no privan a la vida de su rango de algo intrínsecamente valioso y deseable.

El derecho se hizo para el bien común de la humanidad, y ese bien subsume en sí los bienes individuales, incluido el de la libertad en la esfera de lo íntimo; a la cual pertenece la vida individual misma.

Aunque a ello se han solido oponer los perruchistas, existe, pues, efectivamente una función antropológica del derecho; en realidad no es sino la función sociológica o incluso biológica del mismo que vieron a comienzos del siglo xx los grandes jusfilósofos y juristas franceses como Hauriou, Duguit, Georges Scelle y otros.

Y - como también ellos lo señalaron (era la época del rechazo de la vieja jurisprudencia de conceptos) - hay un derecho social, un derecho prelegislativo; hay unos principios regulativos del derecho que promulga la propia colectividad humana, que asumen y refrendan las masas populares, y que puede entrar en conflicto con los promulgamientos de la autoridad legislativa. Verdad es que es a menudo difícil determinar cuáles sean esos principios, mas tampoco está siempre claro el contenido de los preceptos legislativamente promulgados.

Y, más allá de esos principios jurídicos, están ciertas reglas metajurídicas que emanan de la naturaleza misma de las cosas; o sea, un derecho natural.

El error de los antiperruchistas no es creer en los principios generales del derecho ni creer en el derecho natural. Si todo lo que cupiera oponerles fuera el tenor de la legislación positiva francesa a que 
se atuvo la Corte de Casación, ahora, ya hecha la reforma ad hoc de la ley, llevarían razón. No la llevan; porque su error era una equivocación sobre el tenor de los principios generales del derecho moderno y sobre las reglas metajurídicas que, por un derecho natural, constriñen el sentido y la aplicabilidad de los preceptos legislativos.

Nuestra argumentación en este artículo ha desentrañado, en este campo, los principios generales del derecho moderno y las reglas metajurídicas que tienen validez en virtud de la naturaleza misma de las relaciones humanas (o sea, consideraciones de derecho natural). En un sentido opuesto a las tesis antiperruchistas.
Por último, nuestra argumentación se ha atenido al concepto normal y corriente de la individuación del ser humano, que identifica a éste con su cuerpo, manteniéndonos al margen del ficcionalismo jurídico y de cualquier especie de neo-dualismo cartesiano ${ }^{29}$. Eso sí, habría que plantearse si - dados los problemas de desdoblamiento entre el yo presente y el futuro a que nos hemos referido y dadas las dificultades que afloran en torno a este tema de la libertad de vivir - no llevaba razón Derek Parfit al sostener que se había hinchado y sobrevalorado la relevancia de la identidad personal, no siendo ésta necesariamente lo que más nos preocupa e interesa $^{30}$.
1 V. el libro de Marcela Iacub, Penser les droits de la naissance, París, PUF, 2002; ahí se discuten diversas tesis de uno y de otro campo.

${ }^{2}$ Es ese juspositivismo lo que inspira, aunque con dos coloraciones diversas, el libro de Olivier Cayla \& Yan Thomas, Du droit de ne pas naître: à propos de l'affaire Perruche, París, Gallimard, 2002. Estos argumentos son similares a los de los contractualistas que defienden el reconocimiento de derechos —en este caso, con relación al nacimiento- únicamente como resultado de una asunción previa de determinadas obligaciones y sólo por ello: Rosamond Rhodes, «Reproducción, aborto y derechos», en De la vida a la muerte. Ciencia y bioética (edición de David C. Thomasma y Thomasine Kushner), Madrid, Cambridge Univ. Press, 1999, pp. 74-86.

3 Tesis brillantemente defendida por Yan Thomas en el libro citado en la nota anterior.

${ }^{4}$ V. M. Iacub, op. cit. un par de notas más atrás.

${ }^{5}$ V. el trabajo de los autores de este artículo «Los límites del consentimiento y el principio de autonomía», Actas del III Congreso de la Sociedad Española de Filosofía Analítica, Granada (diciembre 2001, ed. por J. J. Acero et al. ), pp. 249-255. ISBN 84-699-6803-3.

${ }^{6}$ El lector podrá apreciar cuánto deben nuestras líneas de argumentación en este artículo a la lectura de los libros de Peter Singer, p. ej., Repensar la vida y la muerte: El derrumbe de nuestra ética tradicional, Barcelona, Paidós, 1997. Trad. Yolanda Fontán (Ed. original en inglés 1994). Véase también a este respecto
Helga Kuhse, The Sanctity of Life Doctrine in Medicine. A Critique, Oxford, OUP, 1987.

7 V. principalmente el libro de Richard Routley, Exploring Meinong's Jungle and Beyond, Canberra, Australian National University, 1980. Richard Routley es el mismo filósofo que Richard Sylvan; cambió de nombre unos años antes de su muerte. También están otras soluciones inspiradas en Meinong, como la de Castañeda, la lógica libre (v., p. ej., «Objects and Existence: Reflections on Free Logic», Notre Dame J. of Formal Logic, v. 30/4, pp. 604-623, 1989). Para un estudio lógico-metafísico de las atribuciones de ser-así sin ser a secas, v. Lorenzo Peña, El ente y su ser: un estudio lógico-metafísico, León, Servicio de Publicaciones de la Universidad de León, 1985.

8 Para una indagación sobre los principios básicos de la inferencia normativa, v. el trabajo de los autores de este artículo «La deducción normativa», Doxa, vol. 23, Universidad de Alicante, 2001, pp. 465-481.

${ }^{9}$ Una objeción a esta tesis nuestra podría ser una consideración de Yan Thomas, en su libro ya citado - a favor de su separación de lo jurídico y de lo natural-, de que en el Derecho romano está prohibido algo imposible: el nexo matrimonial entre parientes en línea recta en cualquier grado; o sea, p. ej., entre una mujer y un tataranieto suyo. En cualquier caso, esa prohibición podía tener sentido en una visión romana arcaica en que los hombres descendían de dioses inmortales; César descendía de Venus.

${ }^{10}$ Notemos que, aun con relación a los derechos de bienestar, hay en general libertad en lo tocante 
a la elección de los medios. No se tiene derecho a pasar hambre; mas no es lícita la alimentación forzosa - salvo casos excepcionales, como cuando quien rehúsa los alimentos está bajo la custodia de otro. Eso muestra lo sinuosa que es la línea de demarcación entre bienes de uno y de otro tipo. En el elenco de casos problemáticos podemos enumerar: los medios de seguridad forzosos; la constitución forzosa de ciertas comunidades o consorcios —vide infra apartado 8-; la aceptación forzosa de ciertos tratamientos médicos en casos de imperiosa necesidad social; la prohibición de ciertas actividades de riesgo personal aunque no se extienda a otros.

${ }^{11} \mathrm{Da}$ igual que se reemplace el consentimiento del afectado por el de otros autorizados legalmente; realmente el consentimiento de otro no es consentimiento; $\mathrm{y}$, de serlo, entonces NP, representado por su madre, rehúsa retroactivamente su consentimiento a que lo hayan hecho nacer.

${ }^{12} \mathrm{~V}$. nuestro artículo «Derecho a la vida y eutanasia: ¿acortar la vida o acortar la muerte?», Anuario de filosofía del derecho, XV, 1998, pp. 13-30.

${ }_{13}$ V. infra, apartado 5.

${ }_{14}$ Respecto a este punto, no vale alegar que la esclavitud es agua pasada. La esclavitud ha sido una situación legal de millones de seres humanos en el mundo civilizado hasta hace 5 generaciones; y todavía existe. Por otro lado, el nacionalsocialismo la restableció de hecho con otro nombre; $y$, de haber prevalecido bélicamente, podría haberla restaurado en amplias zonas del planeta. Luego no hablamos de un pasado que se esfume en la bruma de la lejanía histórica.

${ }^{15}$ Existe una abundante bibliografía sobre la cuestión del «nacimiento injusto» (wrongful birth) y la vinculación de las prácticas de diagnóstico prenatal con cierta concepción neo-eugenésica: Wesley H. Winborne (ed.), Handling Pregnancy and Birth Cases, McGraw-Hill, 1983; Angus Clarke (ed.), Genetic Counseling: Practice and Principles, Routledge, 1994; Roy R. Zimmerman, Jurisprudence and Human Birth. Wrongful Birth, ABBE Pub. Assoc., 1998; Jacques Testart, La procreación artificial, Madrid, Debate, 1994. Un estudio comparativo de la jurisprudencia en este asunto es el de Basil Markesinis, The Law of Obligations, Oxford, Clarendon Press, 1998.

${ }_{16}$ Ciertamente es diverso el caso en el que el derecho a no nacer implica un derecho a no haber sido engendrado o procreado, o sea, a que ni siquiera se constituya el zigoto. Mas en ese caso se aplican nuestros otros argumentos.

${ }_{17}$ A menudo los antiperruchistas aluden a la incongruencia pragmática de quien se queje de vivir; porque (vienen a argumentar de un modo que no deja de recordar tesis de Apel y de Gewirth): quien se queja de algo implícitamente eleva una pretensión al derecho a decirlo; por ende a tener derechos; por consiguiente, a ser sujeto o titular de tales derechos; y, por lo tanto, a vivir; no pudiendo, sin caer en incongruencia, lamentarse de esa misma vida o desear que no se dé, porque eso desharía su queja. Hay muchas respuestas. Una de ellas es que puede ser una contradicción verdadera entre otras. Otra respuesta es que el que se queja de vivir puede dar la vuelta al argumento, haciendo una reducción al absurdo del deber de vivir que se le quiere imponer. En fin, que, en cualquier caso, se desvanece la dificultad si se piensa en tercera persona.

18 V. F. José (Díez) Ausín «Conflictos normativos y análisis lógico del derecho», Anuario de filosofía del derecho, XI, 1994, pp. 393-406.

${ }^{19}$ No es lo mismo el grado de licitud o de prohibición de una conducta u omisión que el grado de su exigibilidad, o sea: la sancionabilidad de esa conducta u omisión. No es lo mismo porque —en virtud de las dos reglas lógico-jurídicas de no-vulneración y del efecto lícito- el grado de licitud o ilicitud de una conducta (u omisión) acarrea un grado de licitud o ilicitud de conductas ajenas que causen o impidan esa conducta propia. La inexigibilidad no se transmite a otros intervinientes. Así, hoy estamos seguros de que no ha de sancionarse una tentativa fallida de suicidio ilícito (constituyendo éste un abuso del derecho a morir, en detrimento de legítimos intereses ajenos o del yo futuro). Mas, en tanto en cuanto sea ilícito, es ilícita toda colaboración o instigación de otros, y a esos otros no se aplica tal inexigibilidad de una conducta ajustada a la norma.

${ }_{20}$ Aunque, según lo hemos visto, eso está mal planteado, y se trata de quejarse de causar un nacimiento en condiciones que hacen impresumible el ulterior consentimiento.

${ }^{21}$ La verdad, sin embargo, es que de lege ferenda lo humanitario sería levantar la injustificada prohibición del incesto y de la filiación incestuosa.

22 Así en poblaciones donde esa incompatibilidad gamética está muy extendida, tampoco se puede obligar a las personas al celibato.

${ }^{23}$ En una nota precedente ya aludimos a esas obligaciones de asociarse. Cabe mencionar: el colegiamiento forzoso para ciertas profesiones (si bien la jurisprudencia constitucional ha querido disimular la colisión entre tal obligación y el derecho de no asociarse aduciendo el ocurrente argumento de que nadie está constreñido a desempeñar una de esas profesiones); la formación forzosa de comunidades de regantes y de consorcios de propietarios; la pertenencia forzosa a una comunidad de vecinos cuando uno compra una vivienda (¿o se alegará que tiene la opción de carecer de morada?). También es forzosa la pertenencia a entes públicos: la comunidad internacional, el estado, el municipio. En muchos países es obligatoria la pertenencia a asociaciones laborales (incluso sin que haya pluralidad de tales asociaciones, para que se dé al menos la libertad para optar por una u otra). En resumen, la libertad de asociación tiene muchos límites; pensamos que un principio regulativo del Derecho moderno es que tales límites han de limitarse al máximo. 
${ }^{24}$ Eso no se extiende a los colectivos totalmente ilícitos, o sea, cuya razón de ser sea la comisión de actos prohibidos o incluso delitos.

${ }^{25}$ Supongamos que la autoridad impone la formación de una cooperativa y que ésta decide que querría no haber existido.

${ }^{26}$ También pueden los pro-vida alegar que la asociación (la vida colectiva) es un bien de libertad (individual), al paso que no lo es la vida (individual). Justamente esto último es lo que se discute.

${ }^{27}$ Por lo tanto, cada colectivo tiene derecho a disolverse. Tal derecho tiene límites, pudiendo chocar con otros derechos e intereses legítimos.

${ }^{28}$ Nuestra argumentación en este apartado ha probado que, aunque no profesáramos la libertad indi- vidual de no asociación, habría razones para estimar que no tienen obligación de existir aquellas asociaciones cuya vida colectiva estaba condenada de antemano a ser desgraciada y miserable. En tales casos sería injusto imponer la existencia de la asociación incluso si, en general, no se admitiera el derecho individual de no asociarse.

${ }^{29}$ Aludimos a la idea de Marcela Iacub, tesis ocurrente e imaginativa, pero que no nos convence. El recurso a la individuación por el proyecto parental no podría nunca resolver casos en los que tal proyecto no se dé o sea irrelevante.

${ }^{30}$ V. Derek Parfit, Reasons and Persons, Oxford UP, 1986. 